\title{
A PRODUÇÃO INFOGRÁFICA DO ESPAÇO E AS REPRESENTAÇÕES DO RIO DE JANEIRO NO
} SECOND LIFE .

- ANDRÉ L. ALVARENGA

Resumo: A infografia, ou imagem de computação gráfica, é um meio de representação que tem como peculiaridade sua capacidade de produzir um espaço tridimensional que se projeta na tela do computador. 0 presente trabalho analisa a espacialidade infográfica desenvolvida pelo Second Life - um programa de computador que constitui um vasto espaç,o, onde muitos cenários podem ser criados e explorados visualmente, podendo tornar-se lugares de encontro e de realização de atividades entre pessoas distantes entre si. A partir da discriminação das diferentes funções desempenhadas pelas diversas esferas representativas que operam simultaneamente diante dos usuários de computador, podemos compreender como 0 espaço virtual torna-se, também, espaço social. A cidade do Rio de Janeiro é inspiração recorrente para cenários virtuais desenvolvidos nessa plataforma e é aqui tomada como estudo de caso.

Palavras Chave: representação, espaço virtual, espaço social, imagem e interface.

Introdução

As representações espaciais são objeto de interesse da Geografia. Elas revelam o efeito do posicionamento subjetivo e da intencionalidade de um indivíduo ou coletividade face às diversas espacialidades ESPAÇO E CULTURA, UERJ, RJ, N. 33, P.127-148, JAN./JUN. DE 2013 vividas. Nesse sentido, um crescente número de geógrafos tem se dedicado à análise de produtos culturais como livros, fotografias, filmes e poesias, como formas de manifestação da imaginabilidade de um lugar ou paisagem. 
Esse termo, imaginabilidade, cunhado por Kevin Lynch (1960) em seu livro A Imagem da Cidade, se refere à imagem pública de um lugar, ou seja, os aspectos socialmente compartilhados associados à sua imagem. $\mathrm{O}$ presente trabalho se situa nessa perspectiva: tem o objetivo de analisar a representação da metrópole carioca numa mídia eletrônica, infográfica e interativa: o Second Life.

\section{O Second Life consiste em um} programa de computador que nos apresenta um mundo infográfico tridimensional onde podemos ter a sensação de 'imersão' indireta, mediada pelo controle dos movimentos de um boneco infográfico, um avatar, que 'habita' esse espaço. O avatar é um boneco que aparece na tela em primeiro plano, normalmente de costas, face ao cenário que aparece ao fundo. O movimento do avatar conduz o movimento da câmera, como se ela estivesse acoplada a seu corpo. Através do deslocamento desse corpo infográfico, podem-se ver os cenários desdobrarem-se na tela tal como se estivéssemos a nos locomover pessoalmente dentro do cyberespaço.

Muitas das cenografias apresentadas são inovações arquitetônicas, urbanísticas ou paisagísticas, mas não em menor número são aquelas que buscam reproduzir ou apropriar-se da imagem de lugares concretos. A cidade do Rio de Janeiro é um desses lugares que emprestaram sua imagem e fama a localidades desse mundo infográfico. $\mathrm{O}$ presente trabalho visa analisar as oito apropriações da imagem da cidade do Rio de Janeiro nesta mídia infográfica e interativa. Ou seja, busco, aqui, compreender que imagens e narrativas da capital fluminense são ativadas pela seleção de formas simbólicas que compõem sua cenografia, visando compreender que funções estas imagens e narrativas exercem na constituição de espaços de interação, afetando a participação (o comportamento) dos usuários/avatares que neles circulam.

Desta forma, o primeiro passo foi analisar com detalhe como, no Second Life, se dá a produção do espaço infográfico, o que habilitou a compreensão dos modos de percepção, encontro, reconhecimento e participação nesses espaços. Compreendido o mecanismo, imergi nesse mundo digital como um flaneur infográfico e me pus a observar as cenas que se desenrolavam diante de mim, desempenhadas pela interação dos usuários e as cenografias apresentadas. Procurei, com base na análise dessas observações, verificar que imagem da cidade do Rio de Janeiro é transmitida, através de denotações e conotações visuais, em cada caso.

\section{A Estruturação do Espaço Virtual}

Os mundos infográficos compõem uma forma bastante peculiar de mídia e diferem, em diversos aspectos, das demais formas de representação. A primeira diferença a ser destacada consiste no próprio suporte material que os permitem aparecer: esses produtos culturais são produzidos e consumidos através de computadores. Portanto, operam em um 
meio multimodal (que possui diversas portas sensíveis de recepção e emissão de sinais), interativo (pois reage à manipulação e permite a conexão com outros usuários) e hipertextual (uma vez que oferece caminhos diversos que permitem aos usuários navegar, isto é, manipular os caminhos da mensagem) (LEVY, 2005).

Lucia Santaella e Winfried Nöth (2005) distinguem três paradigmas da imagem: o préfotográfico, o fotográfico e o pós-fotográfico. $\mathrm{Na}$ primeira categoria, estariam as imagens geradas pelas artes plásticas, como a pintura, a escultura e a arquitetura. Na segunda, estariam as imagens captadas por um mecanismo fotossensível, como a fotografia e o cinema. E na terceira, estariam as imagens infográficas, ou imagens de computação visual, geradas a partir de matrizes logarítmicas de dados. Essas matrizes, ou sistema de matrizes de dados, produzem gráficos $3 \mathrm{D}$ (tridimensionais) animados, ou seja, que podem transformar-se no tempo na medida em que se alteram as variáveis relacionadas.

A partir desses gráficos $3 \mathrm{D}$, é possível produzir modelos e simulações, isto é, réplicas infográficas de objetos, de quaisquer escalas, capazes de simular os movimentos desses objetos no tempo. Dentre os diferentes gêneros de modelos infográficos, destacamos aqui as maquetes eletrônicas, que são réplicas digitais de espaços de ocupação humana. Esses são espaços virtuais, antes de se tornarem visuais, uma vez que a base lógico-matemática precede sua atualização como imagem. São, portanto, espaços que já estavam virtualmente presentes na matriz antes de se converterem em imagem (LEVY, 2005).

A atualização do espaço virtual em imagem visual impressa na tela do computador é feita a partir da determinação de um ponto de visão no espaço virtual, capaz de mirar uma direção e oferecer uma imagem local da paisagem da maquete projetada pela matriz de dados. Podemos obter, desse modo, imagens desses espaços, em perspectiva, a partir de diferentes pontos e visando diferentes direções. Temos, consequentemente, a possibilidade de fazer correr o ponto de vista, percorrendo o espaço virtual como uma câmera, produzindo na tela a imediata atualização da imagem e gerando no espectador-manipulador a sensação de imersão.

Apesar de estas imagens serem geradas por cálculos matemáticos complexos, os usuários comuns não necessitam de quaisquer conhecimentos de programação visual para manipulá-las, pois sua intervenção na base de cálculos é mediada pela imagem que se vê na tela e pelos instrumentos acoplados ao computador. A palavra-chave aqui é interface. Santaella (2004) conceitua interfaces como quaisquer equipamentos mecânicos ou infográficos que operem como zonas fronteiriças sensíveis de 'negociação entre o humano e o maquínico'. A interface é, portanto, o que permite a interação entre pessoas e a matriz de dados gerada por pulsos elétricos controlados que mudam a cada instante. Jester Juul (2005) explica que, no vocabulário da ciência da computação, chama-se máquina de 
estados um tipo de autômato que reage aos diferentes impulsos gerados pelos usuários que o tentam manipular. A união do simbólico/representacional com a máquina de estados resulta na imagem interativa.

A imersão no Second Life se dá de forma indireta, mediada por avatares que controlamos através da interface. Os avatares (Fig. 1) são corpos visuais que, como uma marionete, são comandados pelos usuários e ocupam o espaço infográfico, podendo ser vistos pelos demais usuários. A interatividade do avatar na maquete virtual se constrói a partir da distribuição de hiperlinks ou botões pelo cenário. Os hiperlinks e botões, ao serem acessados, oferecem diversos caminhos a percorrer e ações a realizar. Os hiperlinks podem conduzir-nos a outras localidades e os botões possibilitam a interação local com o cenário e os objetos nele distribuídos, por meio de movimentos corporais automáticos do avatar no espaço circundante.

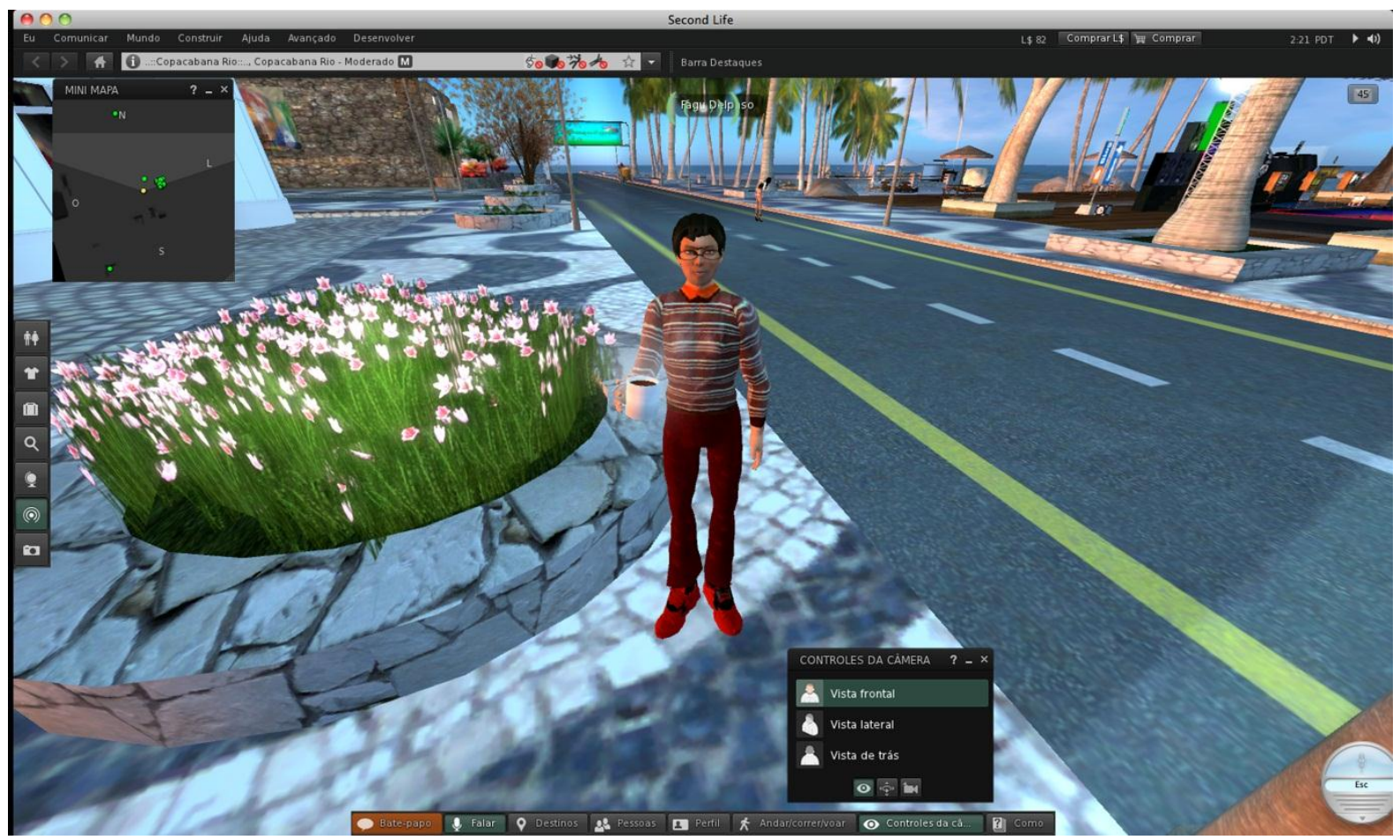

Fig. 1. Imagem frontal de um avatarna ilha Rio Surfe

Destarte, a representação infográfica consiste, principalmente, na criação de uma topologia visual: um mundo de signos dispostos à interação. $\mathrm{O}$ artista desta mídia é um programador de dados, um "engenheiro de

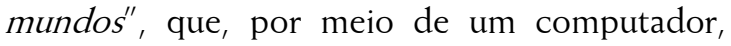
"cria virtualidades, arquiteta espaços de comunicação, organiza equipamentos coletivos de cognição e estrutura a interação sensóriomotora com o universo dos dados" (LEVY, 2005, p. 145). O receptor, por sua vez, deixa de ser mero espectador e torna-se um usuário, que interage e manipula a mensagem como um coautor (LEVY, 2005).

Nesse mundo virtual, contrariamente ao paradigma fotográfico, não existe, como no P.127-148, JAN./JUN. DE 2013 
cinema, um espaço que se descortina igualmente para todos, acompanhando o desenrolar de uma trama ficcional. Esse é um mundo de experimentação individual, subjetiva. Contudo, a possibilidade de encontro entre subjetividades, do reconhecimento do outro e da possibilidade do diálogo ou do conflito entre diferentes traz a esse espaço uma dimensão social.

\section{A Produção do Espaço Infográfico}

Em seu livro, A Produção do Espaço, Henri Lefebvre (2012) destaca que é preciso considerar, primeiramente, as dimensões física, mental e social do espaço. Os mundos infográficos, obviamente, não são físicos. São representações espaciais puramente audiovisuais, espaços geométricos opacos de matriz cartesiana. São, destarte, representações espaciais.

Essa não fisicalidade do espaço virtual constitui sua característica fundadora, pois, a partir dela, diversos efeitos se projetam na caracterização desses espaços como lugares de convivência. Entre esses efeitos, podemos citar os dois mais marcantes: a volatilidade da paisagem construída e a hiperespacialidade. A volatilidade da paisagem se deve ao fato de, em se tratando de obras puramente digitais, estas poderem ser facilmente apagadas (deletadas) e substituídas por outros objetos espaciais. O fator rugosidade e toda a dialética do passado e do presente que caracteriza os espaços construídos são reduzidos, aqui, a um grau mínimo - que se deve exclusivamente à popularidade/rentabilidade de tal espaço. A hiperespacialidade deriva do fato de que esse espaço é uma projeção de cálculos matemáticos, portanto, um espaço abstrato de matriz cartesiana fundado na existência prévia de um espaço geométrico, vazio e estruturado por eixos a partir dos quais um sistema de localização é definido. Um espaço não-físico composto desta maneira permite ser explorado visualmente não apenas por meio de uma câmera virtual que se desloca por uma sucessão de pontos contíguos alinhados, mas, também, a partir de uma câmera que pode surgir em qualquer ponto do espaço, a qualquer momento. O Second Life constitui-se, portanto, como um hiperespaço, um espaço onde, de qualquer localização, podemos acessar diretamente qualquer outra localização, sem recurso ao deslocamento espacial por uma zona de contiguidade. Em outras palavras, esse espaço tem um caráter hiper, no qual todos os seus pontos podem ter conexões com todos os demais.

A partir da união dessas características ligadas à imersão subjetiva dos usuários com a possibilidade de conexão entre computadores, através da Internet, temos a transformação do espaço infográfico em um verdadeiro espaço social. Este é o caso do Second Life e de muitos videogames modernos: a imersão simultânea dos usuários no mundo virtual permite o fenômeno da copresença no mundo infográfico.

O acréscimo da interatividade e da copresença de usuários permite transformar tais 
representações espaciais, em certa medida, em espaços representacionais (que, para Lefebvre [2012], equivalem aos espaços vividos). Certamente, isso não se dá por completo. Uma vez que esses espaços não têm 'vida própria', são como subespaços do espaço-mundo. A não fisicalidade deste mundo o livra das tarefas consideradas biologicamente essenciais. Não nos transferimos verdadeiramente para este mundo porque continuamos física e corporalmente atados no mundo material, mas podemos transferir nossa atenção, nossos pensamentos e afetos para esse espaço. Podemos frequentar cotidianamente $e$, verdadeiramente, habitar esses espaços. Contudo, em se tratando de um espaço que é, também, uma mídia, uma interface que possibilita a interconexão de pessoas distantes em um mesmo lugar, aparece como plataforma para novas instâncias de reprodução social. Essas instâncias se dão no domínio do puramente simbólico, visto que as instâncias de reprodução material escapam à espacialidade visual do Second Life.

Para Lefebvre (2012), o espaço social é o locus da produção e da reprodução sociais e é, ao mesmo tempo, produto desse mesmo processo, pois é construído cotidianamente pelas práticas espaciais. Nesse sentido, para falarmos de uma transubstanciação mais completa do espaço virtual em social, seria preciso que a interação social pudesse participar na produção formal do espaço visual e dos objetos que o compõem. Como veremos a seguir, o Second Life avançou significativamente nessa direção.

\section{Espaços Representacionais}

O Second Life trata-se de um mundo virtual que apresenta duas peculiaridades principais em relação aos demais espaços infográficos interativos: $1-$ a possibilidade de o usuário participar na construção do espaço virtual (tarefa que é feita pelos usuários mais dedicados, que desbravam as ferramentas de edição de maquetes, objetos e animações); 2 - a possibilidade de exploração comercial desses espaços e dos objetos neles inscritos.

Isso se organiza da seguinte maneira: ao inscrever-nos, pela primeira vez, no Second Life, produzimos a imagem inicial do avatar (seu corpo, rosto e vestimenta). Feito isso, imergimos em um cenário inicial com 100 lindens (L\$) (moeda virtual do programa). Se quisermos, podemos adquirir mais lindens mediante compra, através do cartão de crédito. O espaço virtual do Second Life constitui um gigantesco espaço que se abre à exploração, dividido em diversas pequenas ilhas. $\mathrm{O}$ usuário desse mundo virtual pode usar lindens para comprar ilhas, ou terrenos virtuais (mínimo de 3.000,00 L\$). Uma vez proprietário de um terreno, pode-se construir sua cenografia e definir uma série de regras de uso do espaço. Mediante o uso de programas de computação visual compatíveis com o Second Life, o proprietário de um terreno pode construir a paisagem de sua maquete eletrônica. Algumas 
maquetes podem apresentar os mais variados cenários, apresentando paisagens naturais, urbanas ou futurísticas.

Como a construção de maquetes eletrônicas requer investimento de horas de trabalho e sua disposição no ambiente virtual do Second Life requer o pagamento de aluguel em dinheiro real, o que o empreendedor virtual deseja é atrair para o seu espaço o maior número de usuários, para que consumam os produtos disponíveis à venda e possam, também, atrair investimento publicitário, garantindo o pagamento do investimento e, se possível, obtendo algum lucro. Contudo, a hiperespacialidade do Second Life traz consequências importantes para a produção capitalista do espaço, pois dá aos usuários uma liberdade do movimento que impede seu aprisionamento. Dessa forma, práticas espaciais monopolísticas não têm como funcionar nessa plataforma. Assim, apesar da tridimensionalidade do cenário, o fator proximidade também tem sua importância relativizada nesse tipo de espaço mercantil. Se uma localidade é muito frequentada, não significa que muitos usuários vão comprar em suas proximidades, pois todos podem se teletransportar instantaneamente para outras localidades, onde podem encontrar produtos que melhor lhes convêm, ou por preços mais vantajosos.

Como podemos nos teletransportar diretamente para outros cenários por meio de uma ferramenta de busca, um importante atrativo para se angariar frequentadores a uma dada localidade é a definição de topônimos e cenografias que façam referência a temáticas e localidades populares. Dentre as referências temáticas encontradas, podemos destacar Gothan City, Atlântida, Terra do Nunca, Esparta, mas, também, Nova Iorque, Paris, Londres, Tóquio, Roma, Los Angeles e Rio de Janeiro. Todas estas são localidades virtuais de grande popularidade bastante procuradas no Second Life.

Todavia, a grande maioria dos usuários não adquire terrenos no Second Life e estão mais interessados em explorar os espaços e encontrar pessoas para conversar. Ao moldarem a aparência e os gestos do avatar, os usuários exibem uma identidade. Essa identidade pode ser relacionada com a sua própria personalidade no mundo real ou uma representação, como em uma brincadeira de bonecos. Dessa forma, ao se apresentarem visualmente de uma determinada maneira, realizarem ações, se comunicarem com outros e consumirem os produtos que são vendidos nesse espaço, os usuários comuns se tornam, também, coautores na produção dessa representação espacial. Temos, assim, a fundação de um simulacro espacial que dá lugar à teatralização da vida. É, portanto, uma plataforma onde os usuários podem interferir na construção do espaço representado e se relacionar com outras pessoas de $n$ maneiras, mediadas por seus avatares. É a manifestação mais perfeita do que William Mitchell (1998) definiu como Cidade de Bits.

A interação dos avatares com os espaços depende não apenas dos botões e 
hiperlinks, que oferecem possibilidades automatizadas de interação, mas, também, da interpretação e resposta, de cada usuário, ao universo de signos oferecidos pela cenografia e pelos demais avatares que o rodeiam, bem como das condições estabelecidas pelas regras definidas em cada propriedade.

As regras definidas para cada propriedade virtual funcionam como territorialidades, conforme definição de Robert Sack (1986), que visam controlar o acesso ao terreno e o comportamento de seus usuários. Alguns espaços são de uso privado, sendo permitida apenas a presença de avatares de usuários autorizados. Outros são para uso público, apresentando, também, regras de comportamento. As regras de comportamento e acesso podem ser automatizadas, e, portanto, os indivíduos que não as respeitarem são imediatamente teletransportados para outra região do Second Life. Em alguns lugares, sinalizações e comunicações sobre as regras são distribuídas no espaço. Também é comum que esta tarefa seja reforçada por servidores - isto é, avatares controlados por pessoas que operam esses terrenos, que vigiam e comunicam as regras locais aos usuários : aqueles que se negam a se adequar podem ser banidos do terreno, tendo acesso negado nas próximas tentativas de visitação. Um tipo de regra recorrente é a exigência de que os avatares se vistam a rigor de acordo com o uso social definido para o terreno. Uns permitem, outros proíbem a exibição, pelos avatares, de objetos ultrajantes como armas -, nudismo ou animações pornográficas. Há uma série de regras de conduta e censura que vigoram por todo o Second Life, tais como a proibição de qualquer tipo de discriminação racial ou de gênero. $O$ controle é reforçado pelo fato de que qualquer usuário pode denunciar à empresa Linden Labs, criadora do programa, qualquer comportamento considerado ofensivo.

Contudo, apesar de muitos lugares não definirem regras de comportamento, não é difícil perceber que, de modo geral, os usuários buscam adequar a imagem e a animação dos gestos e movimentos corporais dos avatares ao contexto espacial produzido pelo cenário onde se encontram. Cada cenografia aparece, portanto, como um cenário, conforme definição de Gomes (2008), ou seja, compõe uma morfologia que apresenta aspectos simbólicos (formas simbólicas) que ativam um certo grupo de memórias socialmente compartilhadas e comunicam uma mensagem que, por sua vez, contextualiza e influencia formas de comportamento. Os indivíduos localizados em dado contexto cênico também participam da representação a partir da adequação, ou não, de suas ações e performances à cena que se espera ver nos espaços.

As construções no cenário podem abrigar diversos tipos de usos e funções. Essas funções são, em geral, diretamente relacionadas ao caráter audiovisual que constitui esse ambiente. A visibilidade desses espaços permite a distribuição de diversos tipos de signos e, por conseguinte, muitos tipos de mensagens podem ser veiculados, seja por meio da paisagem 
construída, ou mesmo através de sinalizações e objetos informacionais que nela se distribuem. A audibilidade também contribui com a representação espacial. Os espaços são preenchidos por sons: música, som ambientes, ruídos resultantes da movimentação dos avatares e objetos móveis e pelas falas dos usuários, que, por meio de microfones, projetam suas próprias vozes nesse ambiente. Os ruídos e falas são sons pontuais que possuem uma pequena zona de atuação e, portanto, são ouvidos apenas por aqueles que se encontram nas proximidades de seu ponto de projeção.
Uma vez que esses espaços podem ser frequentados por outros avatares (e, portanto, usuários), a dimensão de sua visibilidade passa a ser valorizada por atividades mercantis. Dois tipos de apropriação comercial são comuns: 1 instalações e objetos publicitários que divulgam produtos de consumo material fora do universo infográfico; e 2 - lojas e estandes virtuais onde são vendidos objetos infográficos, de consumo simbólico (Fig. 2). Esses objetos infográficos são dedicados à composição da imagem corporal do avatar, suas roupas, objetos e movimentos corporais, bem como objetos para compor os espaços de sua propriedade.

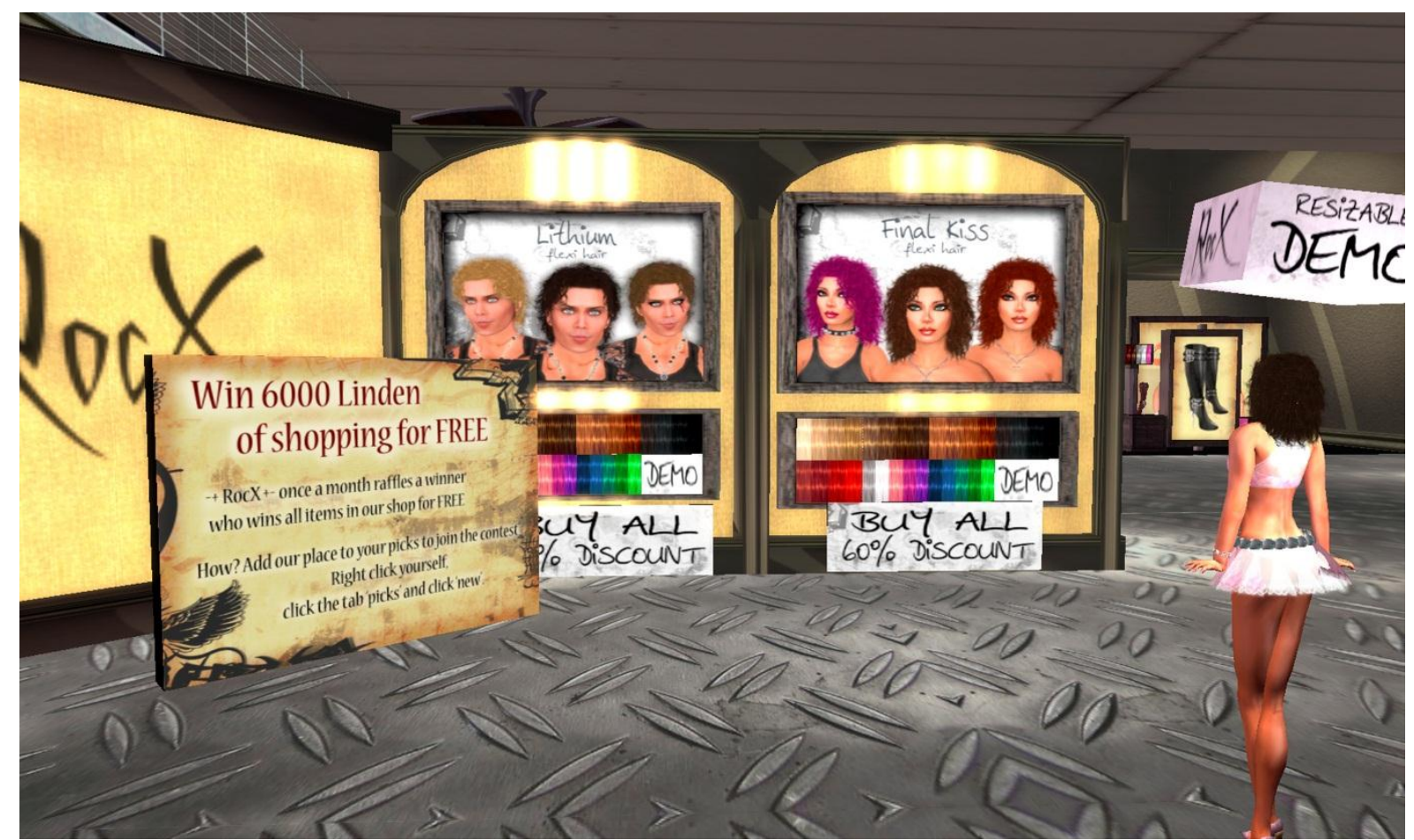

Fig. 2 Imagem de loja que vende produtos de moda digital. Repare que o avatarfeminino da imagem acabou de comprar e vestir um corpo novo.

Contudo, não apenas o uso mercantil caracteriza esse espaço. Outras formas de consumo espacial não produtivas (no sentido da produção de mais-valia) são também muito valorizadas nesse espaço. Um tipo de uso alternativo comum é informativo-pedagógico. Diversas ilhas desse mundo virtual são de propriedade de museus, universidades e escolas, 
que oferecem cursos online, ou apenas distribuem, em seus espaços, instruções e informações a partir do recurso das mídias audiovisuais, como painéis, sons e vídeos (Fig. $3)$.

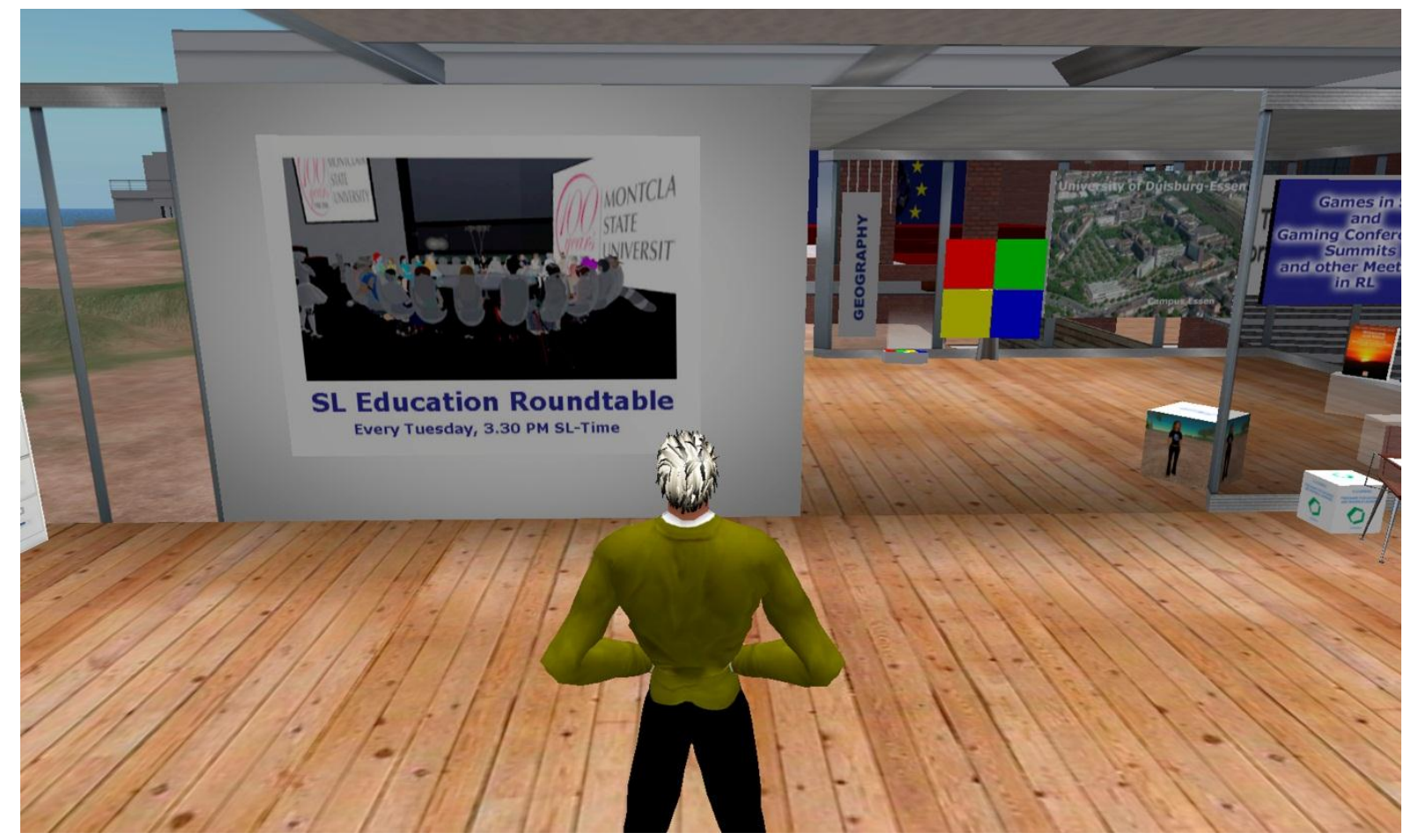

Fig. 3. Imagem de painéis informativos de um espaço pedagógico.

Outro tipo de uso é o lúdico-interativo, em que jogos de representação interpretados pelos usuários permitem criar uma dinâmica ficcional interativa e performativa, na qual a narrativa é construída na medida em que as ações e diálogos vão acontecendo. Algumas ilhas são verdadeiras boates, onde DJs põem músicas para tocar, enquanto os avatares realizam passos de dança. Em outras ilhas, vemos a encenação de peças ou coreografias, na qual os avatares, pelo clique de um botão, se juntam ao grupo de 'atores' que, automaticamente, desempenham ações previamente criadas por algum animador.
Dessa maneira, diferente de uma obra de arte pronta e acabada, em que temos um produto cristalizado (mesmo que em movimento, como o cinema) o qual estabelece, desde sua apresentação, uma cisão entre autor, espectador e obra, o Second Life permite uma coautoria de produtores e usuários, na medida em que os usuários podem produzir ou consumir objetos e roupas, bem como os próprios corpos e gestos de seus respectivos avatares. Uma vez de posse desses objetos e ações visuais, o usuário pode combinar seu uso nos momentos e lugares onde the melhor convier. 
Diana Taylor (2003), em seu livro The Archive and The Repertoire, argumenta que, além da memória formal, armazenada nos arquivos, que funda a história escrita, todos nós temos uma memória corporal e oral, que também atualiza a história por outros meios. Para a autora, as performances artísticas são fundadas no corpo e na sua capacidade de responder aos estímulos externos por meio do acesso a memórias, que lhes apresentam possibilidades de ação. Muitas vezes, a aparência deste corpo e seus movimentos, somados a suas falas, ativam nos espectadores memórias de situações socialmente compartilhadas e permitem leituras. Nesse sentido, a autora contrapõe ao arquivo o repertório, que é esta memória virtual que, quando projetada no corpo, atualiza um cenário o qual não está morfologicamente presente, mas se sobrepõe ao ambiente que circunda a ação e contagia aqueles que o podem contemplar ou dele participar diretamente. Penso que, no caso do Second Life, situação semelhante acontece. $\mathrm{Na}$ maioria dos casos, a cenografia apresenta uma morfologia que introduz um cenário como situação contextual, mas a ação espacialmente coerente dos avatares contribui e reforça o cenário. Em alguns casos, o cenário físico não é tão importante, porém a atividade dos avatares funda um cenário que pertence mais ao domínio da memória-ação (performativa) do que ao da memória-percepção (contemplativa). Contudo, enquanto, nas performances realizadas de corpo físico, o arquivo se diferencia do repertório, o de Second Life é também um arquivo digital, pois todas as ações executadas são previamente arquivadas como comando a ser executado na matriz de dados. Dessa forma, cada vez que uma performance é executada, ela surge como uma repetição de um movimento anteriormente realizado. A novidade e a diferenciação se devem não à execução dos movimentos em si, mas à sua combinação, em resposta a cada diferente situação, além da capacidade de sempre se criar ou comprar novos movimentos.

Temos, portanto, um espaço visual que é, também, um produto social, um produto de práticas espaciais simuladas e combinadas, próprias a um mundo sintético que se apropria da imaginabilidade socialmente difundida de espaços. Enquanto, na representação tradicional, o produto está normalmente destacado do espectador passivo, neste mundo infográfico interativo, vivemos um misto de separação e imersão. Enquanto nossos corpos estão diantes do computador, nossa atenção transita dentro do mundo infográfico apresentado na tela. Habitamos com a mente os lugares audiovisuais do Second Life.

\section{Representações do Rio de Janeiro no mundo virtual}

Desde 2008, venho acompanhando as representações espaciais presentes no Second Life. Nesse período, encontrei oito diferentes localidades virtuais que vinculavam sua imagem e toponímia à representação da cidade do Rio de Janeiro. Decidi analisar os significados dessa referência iconográfica à capital carioca, trazida 
pelos cenários apresentados, em cada caso. Fiz isso verificando, de um lado, as formas simbólicas representativas da cidade do Rio de Janeiro que foram reproduzidas nesses espaços e, de outro lado, as interações dos usuários com a iconografia apresentada como contexto espacial. Pude, desta maneira, encontrar sentidos socialmente difundidos e compartilhados vinculados a certas formas simbólicas características desta metrópole.

A primeira importante constatação é que nenhuma dessas representações buscava ser uma simulação total da cidade do Rio de Janeiro. Não houve a intenção de representar a cidade em sua totalidade, nem como mero espaço 3D, desprovido de vida social. Tal tentativa seria, de qualquer maneira, impossível, visto que um terreno do Second Life normalmente não permite representar mais do que seis quarteirões de uma cidade. De acordo com a semiótica de Peirce (2005), toda representação icônica consiste numa seleção de elementos significativos capazes de sintetizar a imagem do objeto referido. Logo, a representação da cidade é produzida, além de sua toponímia, pela incorporação ao cenário de formas simbólicas socialmente associadas à sua espacialidade.

As oito representações do Rio de Janeiro encontradas no Second Life foram produzidas por autores diferentes, com finalidades diferentes e, como veremos a seguir, cada uma se utiliza das imagens-símbolos da cidade mais convenientes para a construção do espaço temático proposto, em cada caso. Observando diferenças e semelhanças entre os diferentes cenários apresentados, pudemos distingui-los em dois grupos principais: as quatro cenografias que apresentam o Rio como cidade de consumo turístico, sem referência a suas contradições sociais, de um lado; e, de outro, as quatro representações que trazem a favela como elemento de destaque na paisagem.

Nas representações associadas à cidade turística, vemos representados o morro do Corcovado e Cristo Redentor, os Arcos da Lapa, o calçadão de Copacabana, além do Maracanã e o Sambódromo, espalhados no terreno digital, sem imitar a disposição espacial dos objetos espaciais destacados na cidade concreta que serve de modelo (Fig. 4, Fig. 5 e Fig. 6). 

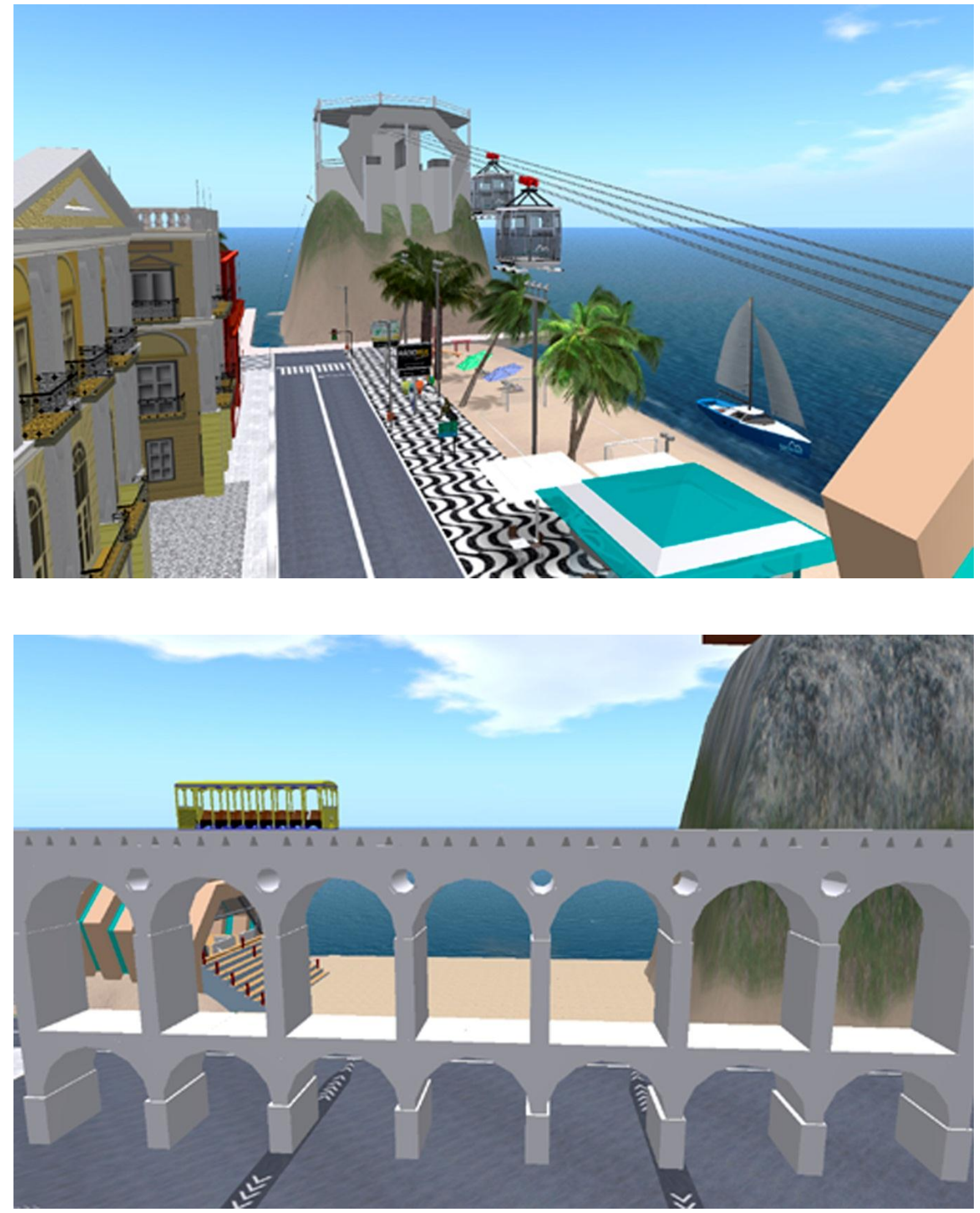

ESPAÇO E CULTURA, UERJ, RJ, N. 33, P.127-148, JAN./JUN. DE 2013

http://www.e-publicacoes.uerj.br/index.php/espacoecultura/ 


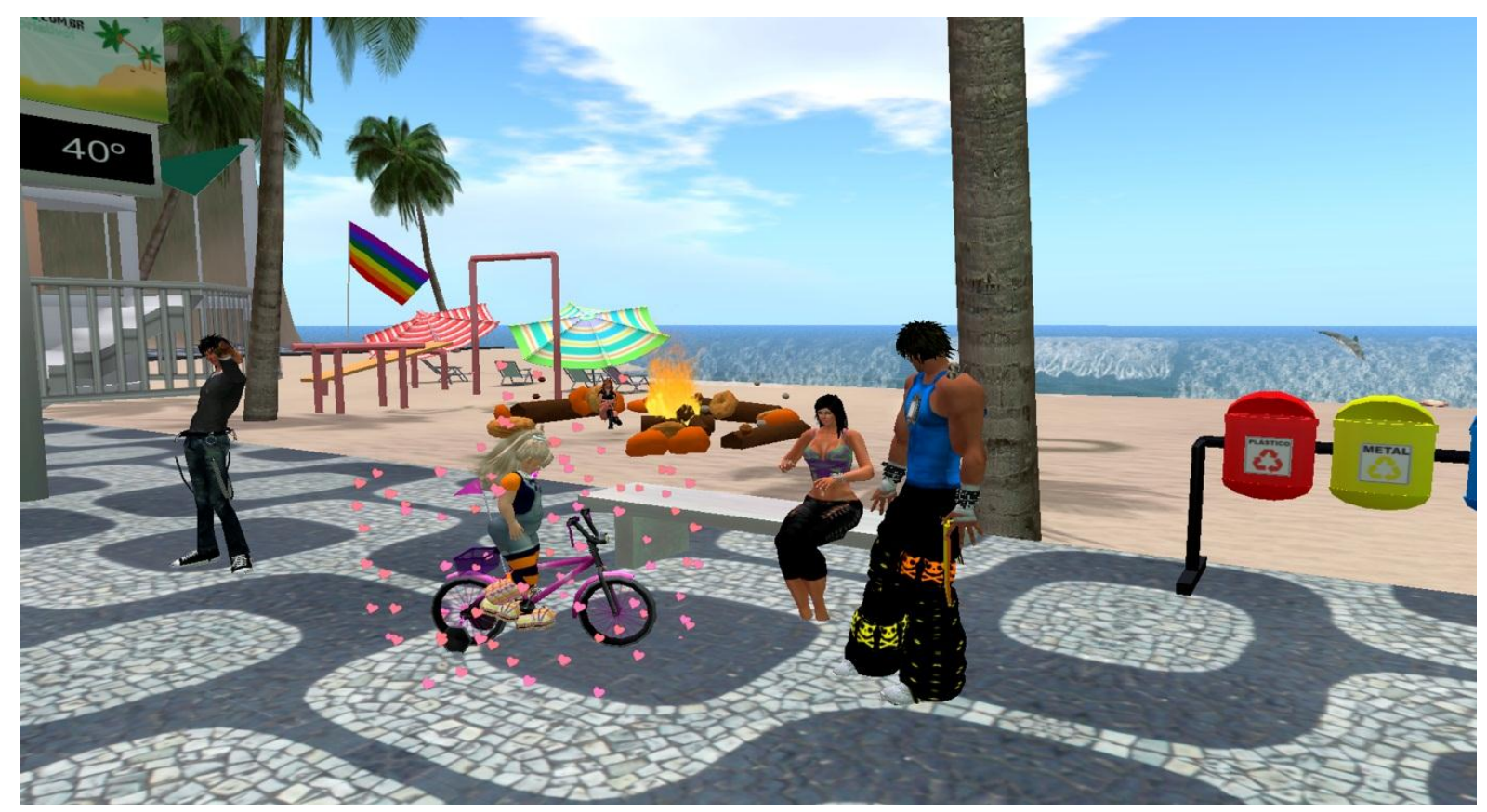

Fig. 4, Fig 5 e Fig 6. Apresentam formas simbólicas mundialmente difundidas da cidade do Rio de Janeiro

Nas representações de favelas, não há qualquer referência a formas simbólicas que demonstrem a especificidade da favela representada. São imagens genéricas de favelas: vemos uma geografia de casas de tijolo sem emboço, em um terreno acidentado. Em alguns muros, encontramos pichações fazendo referência a grupos criminosos ligados ao tráfico de drogas (como CV), a imagem do Fernandinho Beira-Mar, mas também referências à tropa de elite da polícia do Rio de Janeiro, o Bope, tornado famoso mundialmente depois do filme de José Padilha (Fig. 7, Fig. 8 e Fig. 9).

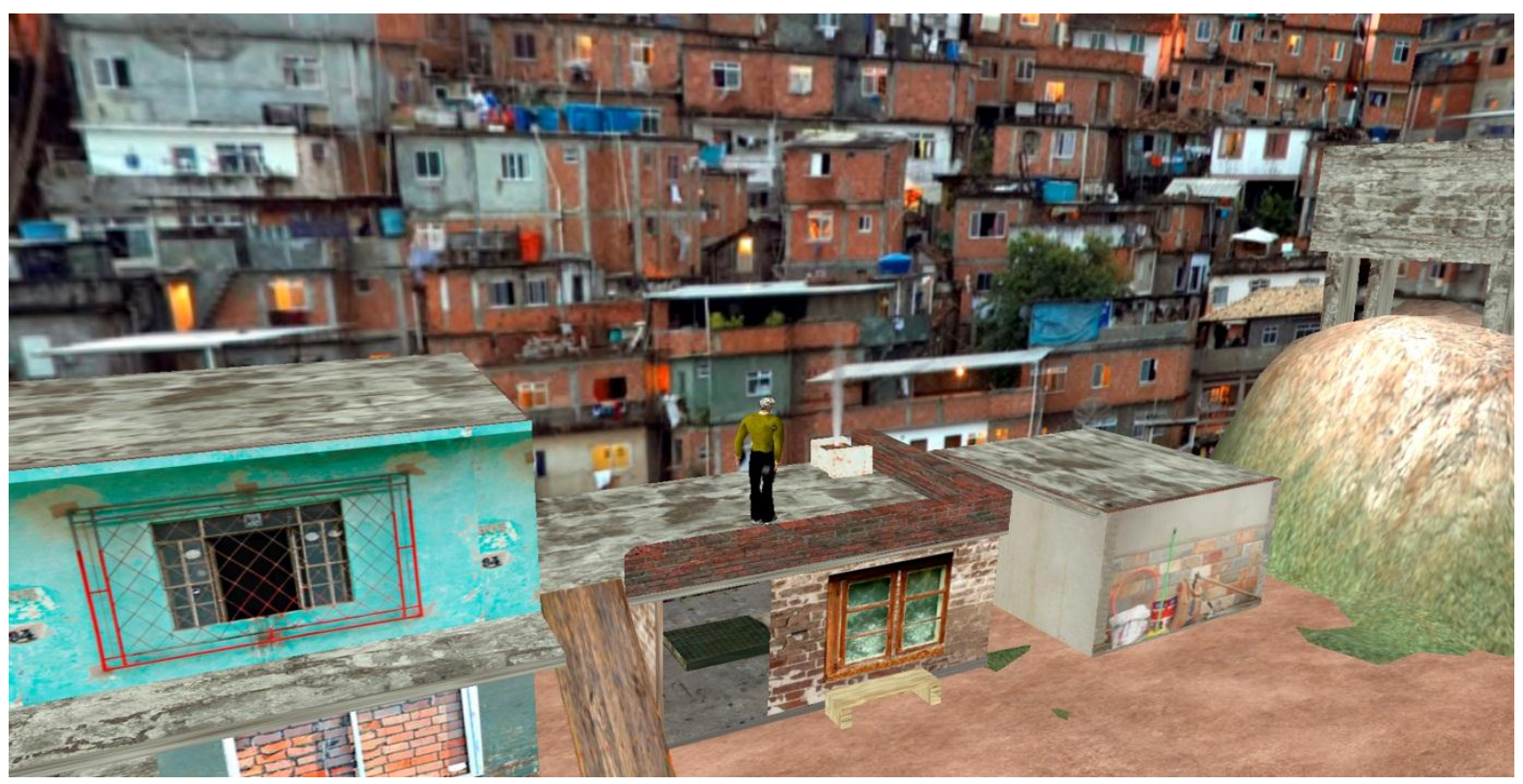

Fig. 7. Imagem de favela, na ilha Complexo do Alemão ESPAÇO E CULTURA, UERJ, RJ, N. 33, P.127-148, JAN./JUN. DE 2013 http://www.e-publicacoes.uerj.br/index.php/espacoecultura/ 


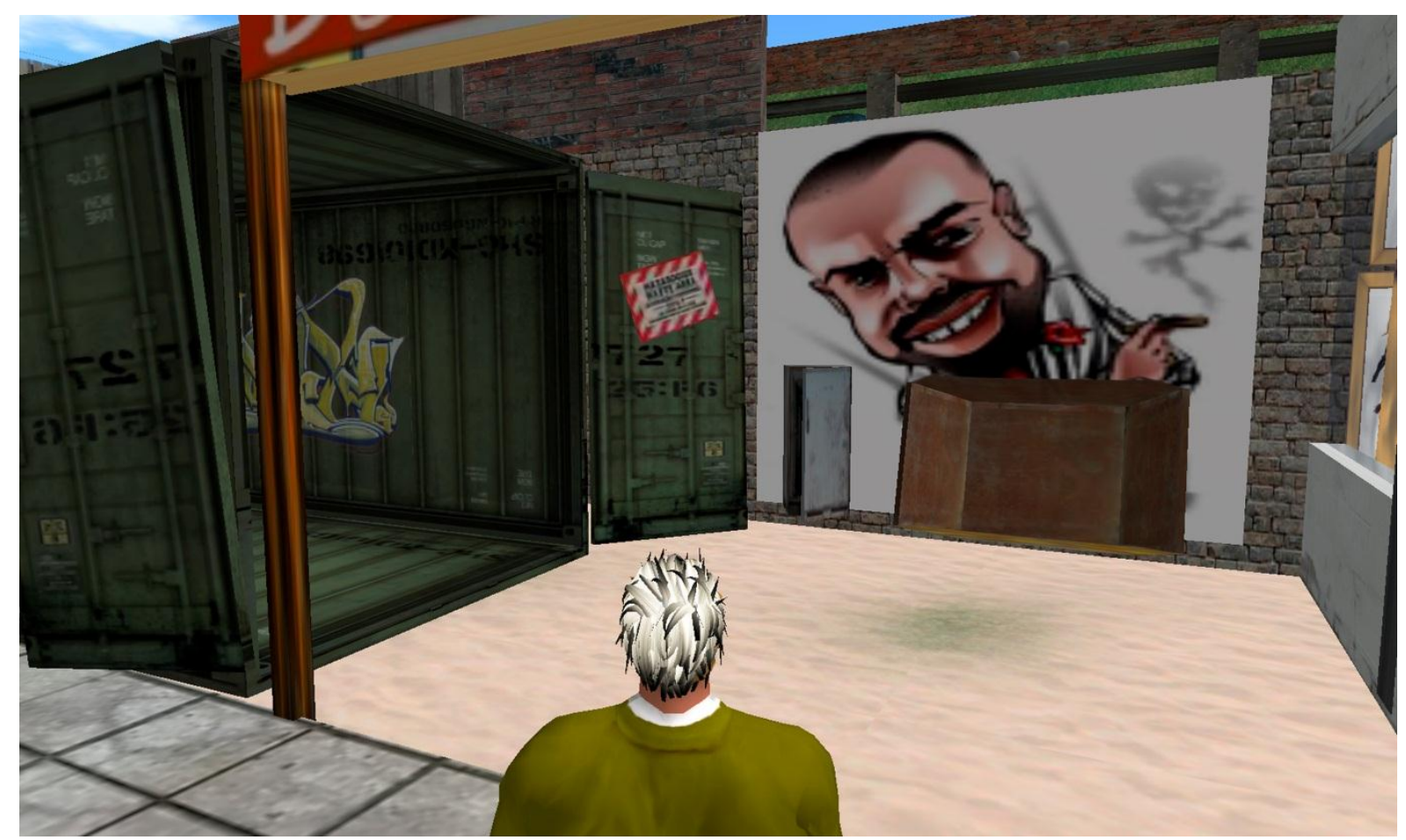

Fig. 8. Imagem de Fernandinho Beira Mar, traficante famoso do Rio de Janeiro

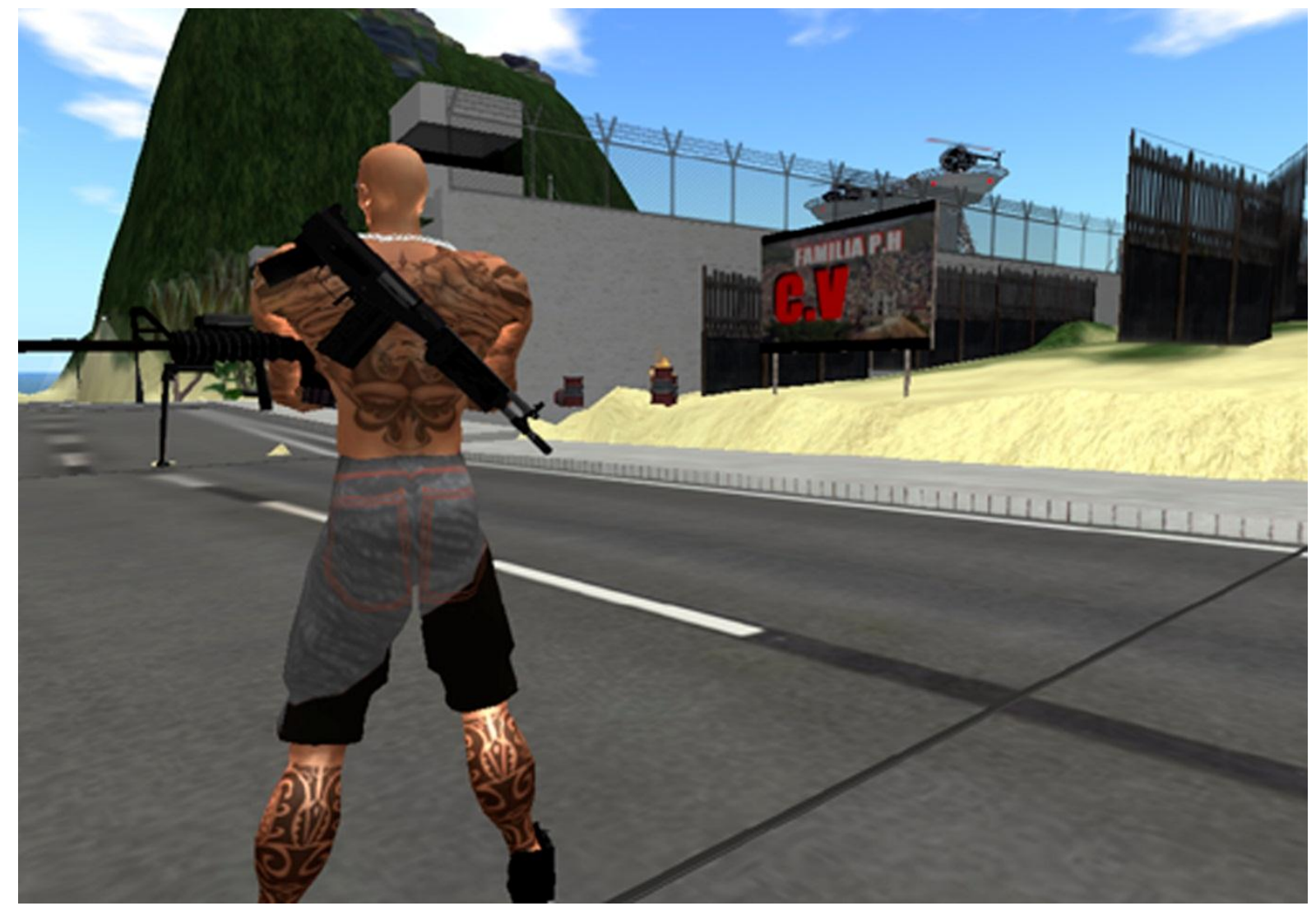

Fig 9. Avatararmado, na ilha Tropa de Elite

Essas duas imagens contraditórias da cidade do Rio de Janeiro, a da cidade maravilhosa de um lado e a da cidade precária de outro, capitalizam as representações da 
cidade nesse ambiente virtual. É interessante notar que essas duas formas de representação são mutuamente excludentes no Second Life. As representações que apresentam as formas simbólicas da cidade cartão-postal não contêm imagens de favelas e vice-versa.

Estas diferentes cenografias não realizam, no mundo virtual, uma função meramente pictórica. Como esses ambientes são voltados para a interatividade, em cada caso, o cenário executa uma função contextual que autoriza tipos de comportamento por parte dos usuários. No caso do cenário Rio de Janeiro, patrocinado pela Secretaria de Promoção ao Turismo da Cidade do Rio de Janeiro, vemos uma maior exploração do potencial didático/informativo do ambiente infográfico. Entre seus edifícios, encontramos um centro de informações turísticas que apresenta fotos e painéis com explicações sobre o carnaval, bem como sobre personalidades, como o carioca Cartola e o mineiro Carlos Drummond de Andrade. Há, secundariamente, um uso comercial, com a presença de lojas de produtos de design infográfico para os avatares e de 'equipamentos urbanos' patrocinados por empresas que operam fora do Second Life. Contudo, devido à forte valorização dos elementos diretamente ligados ao contexto espacial, o comércio existente nesse cenário é também voltado para assuntos relativos à imagem da cidade do Rio de Janeiro. Encontramos, portanto, duas lojas que vendem roupas de praia para avatares e uma loja que vende fantasias de carnaval, roupas típicas da figura do malandro carioca e roupas de profissional da limpeza urbana.

Ambos, praia e carnaval, são imagenssímbolo que também representam e compõem a imagem pública da cidade do Rio de Janeiro. A espacialidade representada no ambiente virtual participa da estratégia de marketing dos produtos de infográficos de moda. Essas imagens são utilizadas como forma de fisgar consumidores de moda virtual, associando um produto a uma espacialidade ali representada.

O comportamento performático dos avatares, observado nesse cenário, oscilava entre a simples conversa entre usuários e a exploração do cenário em seu aspecto visual/informativo, ou interativo, associado à presença de botões e hiperlinks (que oferecem opções de lazer, como deitar em uma espreguiçadeira na areia, sentar na cadeira de um quiosque no calçadão, pedalar uma bicicleta, andar de skate ou voar de asa delta). A representação deste cenário dedicada à cidade do Rio de Janeiro certamente funciona como elemento contextual impulsionador de uma coerência maior entre a imagem e a performance dos avatares e a cenografia contextual apresentada. Os diferentes usuários, ao se deslocarem para essa localização, procuram, em geral, vesti-los com roupas de passeio ou praia, em respeito ao contexto cenográfico apresentado.

As três demais representações do Rio de Janeiro como cidade turística, Rio City Rio, Brazil Rio e Rio Surf, concentram seu cenário na orla de Copacabana e Ipanema, com a adição de poucas formas simbólicas típicas da cidade. Os 
Arcos da Lapa e o Cristo Redendor são as únicas formas simbólicas comuns a todas as representações turísticas do Rio. Quanto mais completa a representação cenográfica da cidade, pude verificar uma maior coerência associativa entre a indumentária dos avatares e a cenografia praiana apresentada. Ou seja, mesmo nas localizações infográficas onde não é regra o uso de certo tipo de traje, vemos os usuários buscarem respeitar a coerência exigida pelo contexto espacial oferecido pelo cenário em que se encontram.

A sociabilidade quase estritamente apoiada na visibilidade dos avatares criou no Second Life uma cultura da representação. A diversidade de estilos iconográficos que se podem comprar para vestir e personalizar o avatar é vasta. É muito comum que os usuários vinculem a indumentária associada aos seus avatares à identidade do grupo que frequentam, mas, também, de acordo com a localidade onde se encontram, criando um tipo de coerência estética associada ao lugar ou ao grupo. Assim, no caso de um cenário praiano, é conveniente vestir trajes de banho.

Nas quatro cenografias de favela carioca presentes no Second Life - Complexo do Alemão, Tropa de Elite, Favela Radical e $5 \times$ Favela - , se destaca um outro uso funcional da paisagem: são áreas de realização de jogos de RPG (Role-Playing Game - jogos em que representamos personagens em uma trama de aventura) e de batalhas de gangues. $\mathrm{O}$ recurso a um cenário de favela, portanto, empresta a esses espaços uma contextualização de zona de guerra, ou paisagem do medo (TUAN, 2005). A imagem da favela é explorada, portanto, como cenário de um campo de batalhas lúdico. Ao tomar emprestada a iconografia típica dos cenários de favela, o designer traz à cenografia um contexto espacial que carrega consigo um texto que baliza tudo que se passa nesse espaço. A mensagem de contextualização explorada pelos quatro cenários de favelas citados é a de urbanos precários, marcados pela guerra entre facções de traficantes de drogas e policiais.

$\mathrm{Na}$ ilha Complexo do Alemão, localizase uma caixa interativa. Caso clicada, permite baixar gratuitamente diversas armas de guerra infográficas interativas para serem vestidas e manipuladas pelos avatares. No caso de um jogo, os usuários devem baixar um programa que adiciona uma interface à interface do Second Life, a qual define a pontuação do seu boneco no jogo de tiro. A relação da imagem dos avatares portando armamentos pesados com o cenário de favela compõe uma unidade representativa que se apoia na imagem socialmente difundida das favelas como lugares associados à criminalidade e à violência. A união de elementos pictóricos do cenário com os adereços iconográficos dos avatares cria uma representação coautoral que forja um cenário de guerra. Esse cenário construído em equipe se apoia no imaginário socialmente difundido da guerra urbana carioca. Tal representação cria uma ponte semiótica que transfere intertextualidades contextuais relativas à espacialidade representada para o cenário de um jogo de batalhas interativo. 


\section{As Imagens da Cidade}

Se o Second Life se apropria de imagens de cidades muito famosas, como o Rio de Janeiro, é importante compreendermos como se dá essa transferência de sentido entre a cidade concreta e sua representação visual no mundo infográfico.

Inúmeras são as imagens das cidades. Nenhum outro objeto geográfico é representado por um número tão extenso de imagens e representações. Contudo, dentre tantas imagens, nenhuma é capaz de dar conta de uma cidade em sua totalidade. Rob Shields (1996), nesse sentido, afirma que a cidade é, primeiramente, o resultado de um ato cultural de classificação. Em sua análise discursiva, Foucault (1989) afirma que qualquer objeto representacional apenas existe mediante um feixe de relações, balizadas por valores e afetos e intermediadas por sistemas de codificação, não preexistindo a si mesmo.

A cidade pode, portanto, ser observada através de uma multiplicidade de regimes de imagem. Podemos conhecer uma cidade através de um mapa ou uma foto de satélite, ou podemos observá-la do alto de uma torre ou de um avião. Contudo, o Bird 's Eye, de Certeau, é tão parcial quanto a visão do flaneur, de Baudelaire, que, ao trafegar pelas suas ruas, só vê a cidade através dos pequenos fragmentos espaço-temporais frequentados.

Ao pensarmos na cidade do Rio de Janeiro, trazemos à mente informações que nos são dadas através de diversas formas representativas, sejam elas formais e criteriosas, ou descompromissadas e preconceituosas, e julgamos tais informações com base em nossas próprias experiências (SHIELDS, 1996; DONALD, 2005). Duncan e Ley (1997) resgatam do pensamento hermenêutico a ideia de que nossa interpretação da representação de uma cidade recorre a dois campos representacionais que habitam nossa memória discursiva: o extratextual - que são nossas experiência pessoais, de situações diretamente vividas e percebidas; e o intertextual - que são os fragmentos de outros discursos e imagens sobre a mesma cidade. Esses dois campos se mesclam e são costurados à leitura de outras representações da cidade, na medida em que referências gerais ou pontuais remetem a essas representações virtuais armazenadas em nossa memória.

Em sentido semelhante, Simmel (2005) argumentava que a leitura de jornais possibilitava, aos citadinos da Berlim de 1920, compartilhamento de inúmeros valores sobre a cidade. A partir dessas leituras socialmente compartilhadas, um imaginário da cidade tornase socializado. James Donald (2005) argumenta, no mesmo sentido, que a literatura dissemina certas estruturas imaginativas sobre a cidade. Donald destaca a influência do trabalho de Charles Dickens sobre o imaginário londrino.

Dessa forma, apesar de cada indivíduo construir, em seu imaginário, uma imagem própria da cidade, a produção de certos discursos, filiados a certas estruturas de pensamento, e sua disseminação na sociedade 
através dos vários meios de comunicação permitem que certas leituras da cidade se tornem hegemônicas. Kevin Lynch (1960) defende que há uma certa imaginabilidade da cidade que é compartilhada e difundida em larga escala, moldando certas formas de pensar e agir na cidade.

São aspectos parciais e compartilhados dessa imaginabilidade da cidade do Rio de Janeiro que parecem ter sidos destacados e utilizados no Second Life, como forma de criar um espaço virtual de convivência e diversão. É necessário que haja um certo grau de compartilhamento de ideias e leituras sobre a capital fluminense para que ela possa ser representada em um meio de comunicação interativo e compreendida por usuários, muitos dos quais só conhecem o Rio de Janeiro através de notícias, filmes e relatos. Essas ideias compartilhadas resultam menos da vivência direta do espaço carioca do que da superposição de imagens e discursos, vinculados pelos meios de comunicação social, que se mesclam. Os topônimos Tropa de Elite, Complexo do Alemão e $5 x$ Favela são reveladores do quanto a televisão e o cinema, além dos eventos históricos de caráter midiático - como a tomada do Complexo do Alemão pelas forças policiais são fundamentais pavimentadores do imaginário social sobre as favelas.

Bridge e Watson (2005) destacam que há uma tradição de apresentar cidades ora como utópicas, ora como distópicas, enfatizando o encantamento, o desejo e a razão, no primeiro caso, ou sublinhando temores, criminalidade e escuridão, no segundo. São justamente essas duas visões polarizadoras da cidade do Rio de Janeiro que vemos reproduzidas no Second Life.

Mas essa representação polarizada da cidade não nasce nessa representação infográfica interativa. Se perguntarmos a qualquer brasileiro que palavras lhes vêm à mente quando pensam na capital fluminense, as respostas mais comuns são diretamente associadas a essa mesma dicotomia: beleza e lazer de um lado, violência e medo de outro.

É interessante verificar que, se analisarmos as oito representações da cidade do Rio de Janeiro no Second Life em conjunto, podemos ver que a imagem de uma cidade turística, cheia de elementos simbólicos atrativos e livre de contrastes, em oposição à sua sombra revelada pela representação da favela, acaba por trazer à tona a imagem, também socialmente difundida, do Rio de Janeiro como uma cidade partida, conforme definição do jornalista Zuenir Ventura. Tal partição está presente nas mais diversas formas de representação da cidade, desde o filme Rio, 40 Graus, de Nelson Pereira dos Santos, à música de mesmo nome, interpretada pela cantora Fernanda Abreu, passando pelos jornais e telenovelas.

Essa dicotomia domina a imaginabilidade do Rio de Janeiro e tem forte reverberação tanto em obras de interesse cultural, como as citadas acima e as analisadas no presente trabalho, como na esfera das políticas públicas, hoje dominadas por ações 
midiáticas. A imaginabilidade polarizada da capital carioca pode ser reconhecida, portanto, como um ser social, um tipo de fantasmagoria ou virtualidade que paira nas mentes de cada um de nós e, vez por outra, toma forma, se atualiza em um evento social ou produto puramente simbólico. É essa imaginabilidade socialmente difundida que autoriza, por exemplo, a construção de muros para limitar as favelas, ou a imposição brutal da força policial nesses espaços. São medidas que, além de seu conteúdo direto e específico, visam atingir o imaginário e mostrar que se está lutando contra as distopias, contra as paisagens do medo, numa tentativa de levar luz (de holofotes) e a razão (das balas e canhões) às áreas sombrias dominadas pelo espectro da violência.

\section{Algumas Conclusões}

As oito diferentes representações nos mostram um pouco da complexidade da espacialidade criada pelo espaço virtual do Second Life. Os diversos graus de coautoria e a interatividade em tempo real entre milhares de usuários entre si com um cenário virtual são os componentes mais ricos e mais novos trazidos por este meio de representação. A possibilidade de produzir sempre novas representações da cidade e a confrontação de tais representações com a performance corporal-espacial desempenhada pelos avatares revelam não apenas pontos de vista subjetivos e individualizados de cada usuário, mas, principalmente, valores compartilhados atrelados à imagem da cidade.

Muitas são as possíveis representações da cidade a serem criadas e, portanto, muitos possíveis olhares sobre a cidade podem ser revelados. Contudo, nas mais diversas representações encontradas da cidade do Rio de Janeiro, vemos a disseminação de uma imagem comum: a da cidade partida. Cada metade da imagem, a utópica e a distópica, oferecem, em cada caso, funções diferentes relativas ao tipo de interatividade que se quer proporcionar. Podemos dizer que, mais importante que a produção de uma imagem da cidade, os usuários do Second Life são dedicados ao consumo e reprodução de estereótipos já socialmente difundidos.

O mundo infográfico é, portanto, duplamente virtual. É virtual por ser uma matriz de dados, antes de se tornar imagem, mas é também virtual porque aparece para seus consumidores-produtores como um espelho de visões socialmente difundidas do mundo, no qual nossas visões imaginárias comuns são projetadas e atualizadas. Enquanto meu corpo real olha e manipula a imagem virtual que se atualiza na tela, a imagem que aparece diante dos meus olhos torna reais as imagens e discursos virtuais que armazenamos como memória latente. Nesse processo, vemos a sobreposição das imagens que incorporam a memória social hegemônica da cidade do Rio de Janeiro. As memórias mais subjetivas da cidade são ofuscadas pelo próprio fenômeno comunicacional. Na busca por comunicar-se, 
indivíduos diferentes que habitam os mesmos espaços públicos virtuais acabam por trilhar os caminhos da memória social, de onde uma imagem pública é compartilhada por todos. Essa imagem pública, comum a todos, é bastante clara e de fácil detecção porque amplamente difundida pela mídia de massa.

\section{REFERÊNCIAS BIBLIOGRÁFICAS}

BRIDGE, G. e WATSON, S. Introduction: Reading City Imaginations. In: BRIDGE, G. e WATSON, S. The Blackwell city reader. Orford: Blackwell, 2005. p. 3-10.

DONALD, J. The Immaterial City: Representation, Imagination and Media Technologies. In: BRIDGE, G. e WATSON, S. $A$ Companion to the City. Oxford: Blackwell, 2005. p. 46-54.

DUNCAN, J. and LEY, D. Introduction - Representing the Place of Culture. In: DUNCAN, J. and LEY, D. (Eds.), Place/culture/representation. London: Routledge, 1997. p. 1-21.

FouCAUlT, M. A Arqueologia do Saber. Rio de Janeiro: Forense, 1989. 239p

GOMES, P. C. Cenários para a Geografia. In: CORRÊA, R. L. e ROSENDAHL, Z. orgs, Espaço e Cultura: Pluralidade Temática. Rio de Janeiro: EdUerj, 2008

JUUL, J. Half-real. Massachusetts: MIT, 2005. 233p.

LEFEBVRE, H. The Production of Space. Oxford: Blackwell, 2012. 454p.
LEVY, P. Cibercultura. São Paulo: Editora 34, 2005. 260p.

LYNCH, K. A Imagem da Cidade. São Paulo: Martins Fontes, 2006. 227p.

MITCHELL, W. M. City of Bits. Massachusetts. MIT Press, 1998. 225p.

NÖTH, W.; SANTAELLA, L. Imagem: cognição, semiótica, mídia. São Paulo: Iluminuras, 2005. 222p.

PEIRCE, C. S. Semiótica. São Paulo: Perspectiva, 2005. 337p

SANTAElla, L. Culturas e Artes do Pós-Humano. São Paulo: Paulus, 2004. 357p

SHIELDS, R. A Guide to Urban Representation and What to Do About It: Alternative Traditions of Urban Theory. In: KING, A. (org.) Re-Presenting the City-Ethnicity, Capital and Culture in the $21^{\text {st }}$-Century Metropolis. Nova Iorque: New York University Press, 1996. p. 227-252

SIMMEL, G. The Metropolis and Mental Life. In: BRIDGE, G. e WATSON, S. The Blackwell City Reader. Oxford: Blackwell, 2005. p. 11-19.

SACK, R. Human Territoriality: Its Theory and History. Cambridge: Cambridge University Press.

TAYLOR, D. The Archive and the Repertoire: Performing Cultural Memory in the Americas. Durham, NC: Duke University Press, 2003.

TUAN, Y.F. Paisagens do Medo. São Paulo: Unesp, 2005. 376p. 
ABSTRACT: INFOGRAPHY, OR COMPUTER GRAPHICS, IS A MEDIUM OF REPRESENTATION THAT HAS THE PECULIARITY OF PRODUCING A TRI-DIMENSIONAL SPACE THAT IS PROJECTED ON THE COMPUTER SCREEN. THE PRESENT WORK ANALYSES THE INFOGRAPHIC SPATIALITY DEVELOPED BY SECOND LIFE - A COMPUTER PROGRAM THAT CONSTITUTES A WIDE SPACE, WHERE MANY CENARIOS CAN BE CREATED AND VISUALLY EXPLORED AND ALSO GIVE ROOM TO MEETINGS AND THE REALIZATION OF MANY DIFFERENT ACTIVITIES BETWEEN PEOPLE DISTANT FROM EACH OTHER. FROM THE DISCRIMINATION OF THE DIFFERENT FUNCTIONS PLAYED BY THE MANY REPRESENTATIVE LAYERS THAT WORK SIMULTANEOUSLY, IN FRONT OF THE COMPUTER USERS, WE CAN COMPREHEND THE WAY THE VIRTUAL SPACE BECOMES A SOCIAL SPACE. THE CITY OF RIO DE JANEIRO IS A RECURRENT INSPIRATION FOR VIRTUAL SCENARIOS DEVELOPED ON THIS PLATFORM, AND IT IS TAKEN HERE AS A CASE STUDY.

KEY-WORDS: REPRESENTATION, VIRTUAL SPACE, SOCIAL SPACE, IMAGE AND INTERFACE.

LA PRODUCTION INFOGRAPHIQUE DE L'ESPACE ET LES REPRÉSENTATIONS DE RIO DE JANEIRO DANS SECOND LIFE

RÉSUMÉ: INFOGRAPHIE, OU COMPUTATION GRAPHIQUE (CG), EST UN MOYEN DE REPRÉSENTATION QUI A COMME PARTICULARITÉ SA CAPACITÉ À PRODUIRE UN ESPACE TRIDIMENSIONNEL QUI EST PROJETÉ SUR L'ÉCRAN DE L'ORDINATEUR. CET ARTICLE ANALYSE LA SPATIALITÉ INFOGRAPHIQUE DÉVELOPPÉE PAR SECOND LIFE - UN LOGICIEL QUI EST UN VASTE ESPACE, OÙ NOMBREUX SCÉNARIOS PEUVENT ÊTRE CRÉÉS Et EXPLORÉS VISUELLEMENT, PEUT DEVENIR DES LIEUX DE RENCONTRE ET DE RÉALISATION D’ACTIVITÉS ENTRE PERSONNES ÉlOIGNÉES. DE LA REPARTITION DES DIFFERENTS ROLES JOUES PAR LES DIFFERENTES SPHERES REPRESENTANTES FONCTIONNANT SIMULTANEMENT DEVANT LES USAGERS D'ORDINATEUR, ON PEUT COMPRENDRE COMMENT L'ESPACE VIRTUEL DEVIENT AUSSI L'ESPACE SOCIAL. LA VILLE DE RIO DE JANEIRO EST UNE INSPIRATION RECURRENTE POUR LES SCENARIOS VIRTUELS DEVELOPPES SUR CETTE PLATEFORME ET EST PRISE ICI COMME UNE ETUDE DE CAS.

MOTS-CLÉS: REPRÉSENTATION, ESPACE VIRTUEL, ESPACE SOCIAL, IMAGE ET INTERACTIVITÉ 